\title{
Een woordsoort als brug
}

\section{A part of speech as a bridge}

\section{Camiel Hamans}

\begin{abstract}
The aim of this paper is to show that blends or portmanteau words form an intermediate category between monomorphemic and polymorphemic words.

First, it will be shown that one must distinguish between two types of concatenations of portions of two words. On the one hand formations that combine the first portions of the two source words and on the other hand words in which the first part of the first source word is combined with the final part of the second. These last group are real blends. The first one is better called clipped compounds, complex clippings or stub compounds.

Both groups show a righthand head. Clipped compounds appear to be a subcategory of compounds and follow the Compound Stress Rule. In blends the right part of the final form is also the head. However, blends copy the prosodic and syllabic structure of the second source word. Whereas compounds consist of at least two prosodic or phonological words, blends consist of only one. This leads to the conclusion that blends can best be described as an intermediate category between compounds and simplex words.

Most of the examples described in this paper come from Dutch, however, some German and English examples are also discussed. Blending operates in a similar way in these languages. Therefore, the analysis presented here does not claim universal validity.
\end{abstract}

\section{Keywords}

Blends, Clipped compounds, Stub compounds, Prosodic word, Prosodic morphology, Word formation 


\section{Inleiding}

In zijn bekende introductie tot de linguïstiek Taalwetenschap (1959: 22) stelt E.M. Uhlenbeck dat het de eerste taak is van de morfologie om te bepalen welke woorden polymorfematisch zijn en welke monomorfematisch. Met een impliciete verwijzing naar de biologie noemt Uhlenbeck deze twee soorten geleed dan wel ongeleed. In deze studie zal aangetoond worden dat dit onderscheid geenszins absoluut is.

Wie de moeite neemt een tijdje nieuwe of ongebruikelijke woorden die in de media opduiken te noteren, moet concluderen dat er weinig systematiek in de volgende groepen nieuwvormingen lijkt te bestaan. Naast elkaar komen bijvoorbeeld zowel flex (1a) als flexi (1b) voor.

(1) (1a)

$\begin{array}{lllll}\text { (1a) } & & (1 \mathrm{~b}) & & \\ \text { flexcontract } & \leftrightarrow & \text { flexitariër } & <\text { flexibel } & + \text { vegetariër } \\ \text { flexzorg } & \leftrightarrow & \text { flexigaam } & <\text { flexibel } & + \text { monogaam } \\ \text { flexkiezer } & \leftrightarrow & \text { flexicurity } & <\text { flexibel } & + \text { security }\end{array}$

De lexemen flex en flexi zijn beide van hetzelfde adjectief flexibel afgeleid. Immers een flexcontract is een flexibel contract, net zoals een flexitariër een vegetariër is die nogal flexibel met zijn principe omspringt. Het verschil lijkt echter dat flex combineert met een volledig woord (de nomina contract, zorg en kiezer), terwijl flexi zich verbindt met een ingekort deel van een volledig woord, -tariër, -gaam en -curity. Moet een eerste conclusie daarom zijn dat flex een ingekort adjectief is, dat zelf ook weer als adjectief functioneert en zodoende in samenstellingen kan voorkomen net als blauw in Blauwbaard en blauwkous? Volgens het woordenboek inderdaad. Van Dale (2015) geeft voor flex, naast enige andere hier niet relevante betekenissen, "verkorting van flexibel, ook als eerste lid in samenstellingen".

Flexi komt niet voor in echte samenstellingen, maar treedt in de hier gepresenteerde voorbeelden op in combinatie met een volgend ingekort woord. Op het eerste gezicht lijkt het eerder een prefix dan een verkort adjectief. Maar wat dan met de vorm flexivoor "een deeltijdvegetariër"? Dit woord zou dan uitsluitend uit twee gebonden morfemen bestaan, een prefix en een suffixachtig element; iets dat in strijd is met alle wetten van de morfologie, die zeggen dat in afleiding minstens liever een deel een vrij morfeem moet zijn. Wellicht dat het daarom beter is te onderzoeken of vormen als flexitariër misschien blends zijn.

\section{Blends}

Blends, ook wel genoemd portmanteaus, contaminaties, samensmeltingen of kofferwoorden, kunnen zich nauwelijks in de aandacht van Nederlandse morfologische onderzoekers verheugen. Booij en Van Santen (2018: 26-27) bespreken een enkel voorbeeld en geven aan dat er bij samensmeltingen een zekere mate van geleedheid valt te bespeu- 
ren, maar een tot een nadere analyse van blends gaan ze niet over. Booij (2019: 11 \& 140-141) vermeldt het verschijnsel slechts. Ook in traditionele Engelstalige morfologische handboeken wordt blending als onbelangrijk en onsystematisch terzijde geschoven. Een citaat uit Marchand (1968: 451) volstaat.

Blending can be considered relevant to word-formation only insofar as it is an intentional process of word-coining. We shall use the term here to designate the method of merging parts of words into one new word, as when $\mathrm{sm} / \mathrm{oke}$ and $\mathrm{f} / \mathrm{og}$ derive smog. Thus blending is compounding by means of curtailed words. However, the clusters $s m$ and $o g$ were morphemes [sic!] only for the individual speakers who blended them, while in terms of the linguistic system as recognized by the community, they are not signs at all. Blending, therefore, has no grammatical, but a stylistic ${ }^{1}$ status. The result of blending is, indeed, always a moneme, i.e. an unanalysable, simple word, not a motivated syntagma. Once the blend smog has been formed, it ceases to contain the two (curtailed) morphemes which the word coiner intended to combine in it. Unless speakers have received extralingual information about the composition of the blend, such words as brunch $($ br/eakfast $+l /$ unch $)$, smaze $(s m / o k e+h / a z e)$, and other are simple words, the subject matter of lexicology.

Vergelijkbare negatieve opvattingen treft men onder meer ook aan bij Aronoff (1976), Bauer (1983, 1988), Spencer (1991), Rainer (1994) en Haspelmath (2002). Ondanks al deze 'verbanningen' uit de morfologie, is het zeer wel mogelijk systematisch onderzoek te doen naar blends.

Het Nederlands heeft veel blends uit het Engels overgenomen, zoals bijvoorbeeld brunch, smog, advertorial en stagflatie, een leenvertaling van het Engelse stagflation. Toch zijn er ook oorspronkelijk Nederlandse blends, zoals:

$\begin{array}{llll}\text { brusjes } & < & \text { broers } & + \text { zusjes } \\ \text { conculega } & < & \text { concurrent } & + \text { collega } \\ \text { flexitariër } & < & \text { flexibel } & + \text { vegetariër } \\ \text { krommunicatie } & < & \text { krom } & + \text { communicatie } \\ \text { vechtscheiding } & < & \text { vecht }(e n) & + \text { echtscheiding }\end{array}$

In (3) is aangegeven welke delen van de beide basiswoorden gewist worden en welke delen gecombineerd worden tot de uiteindelijke blend. De 'overblijvende' delen zijn gecursiveerd. Vooralsnog lijkt er weinig systematiek te vinden in wat er geschrapt wordt en wat er overblijft.

$\begin{array}{llll}\text { brusjes } & < & \text { br oers } & +\mathrm{z} \text { usjes } \\ \text { conculega } & < & \text { concu rrent } & + \text { co llega } \\ \text { flexitariër } & < & \text { flexi bel } & + \text { vege tariër } \\ \text { krommunicatie } & < & \text { kr om } & + \text { c ommunicatie } \\ \text { vechtscheiding } & < & \text { vecht } & + \text { echtscheiding }\end{array}$

1 Vet $\mathrm{CH}$. 
Bij sommige van deze voorbeelden blijkt er een overlappend deel te zijn tussen de beide basiswoorden. Deze overlappende delen zijn in (4a\&b) onderstreept. Volgens Grésillon (1984: 15) en Fradin (2000: 27), die beiden onderzoek gedaan hebben naar Franse 'mots-valises', is een overlap tussen de beide basiswoorden een conditio sine qua non voor een geslaagde blend.
(4a) krommunicatie $<$
vechtscheiding $<$ $\begin{array}{ll}\text { krom } & + \text { communicatie } \\ \text { vecht } & +\underline{\text { echtscheiding }}\end{array}$
(4b) conculega $<\quad$ concurrent + collega

In (4a) is de overlap evident. In (4b) is die veel minder duidelijk. Weliswaar bevatten beide basiswoorden een $/ \mathrm{o} /$ in de eerste syllabe, maar de eerste syllabe van het tweede basiswoord, collega, moet gewist worden om de uiteindelijke blend te produceren. Bovendien blijkt een overlap geenszins een vereiste te zijn voor een geslaagde Nederlandse blend, zie de voorbeelden brusjes en flexitariër.

Kastovsky (2009: 12) claimt dat geslaagd blends normaliter moeten verwijzen naar referenten die een mengeling of kruising zijn van de referenten van de basiswoorden. In het geval van gaap of scheit, een kruising van schaap en geit, lijkt zijn observatie correct. Ook in het Engels (5) en Frans (6) wordt dit type blends aangetroffen.

(5)

smog
spork
brunch
geep
shoat
camelphant

(6)

Toch lijkt Kastosvky's generalisatie niet correct. Brusjes, om slechts een voorbeeld te geven, verwijst immers op geen enkele wijze naar een fysieke kruising in de realiteit. Brusjes is de optelsom van broers en zusjes, eerder een combinatie dan een mengeling, zoals blijkt uit de geaccepteerde woorden brusjesregeling en brusjesdag.

(7a) Brusjesregeling is een officiële regeling waarbij een kind voorrang krijgt bij toelating tot een school in bepaalde gemeentes, omdat een oudere broer of zus al op die school zit

(7b) Brusjesdag is een familiebijeenkomst voor broers en zusters

2 De uitspraak van dit woord is volgens wiktionary.org [sã.glo.fõ] waarbij zowel het slotsegment van het eerste basiswoord, -ier getrunceerd is als de beginconsonant /k/ van cochon (https://fr.wiktionary.org/wiki/ sanglochon). De spelling van sanglocochon met vier lettergrepen in plaats van de drie uitgesprokene is dus misleidend. 
Brusjes kan qua betekenis en vorm beter vergeleken woorden met een Engelse vorm als Oxbridge van Oxford en Cambridge. Ook hier gaat het niet om een hybride kruising van beide traditionele universiteitssteden, maar om een combinatie van eigenschappen die beide steden kenmerken.

\section{Twee typen}

Aangezien een eerste oppervlakkige analyse van de gewiste en de resterende delen van basiswoorden van blends niet tot een heldere systematiek leidt en de voorwaarden die Grésillon, Fradin enerzijds en Kastovsky anderzijds formuleren voor een geslaagde blend evenmin, is het raadzaam de mogelijke types woordversmeltingen die onder de noemer blend samengevat worden nader te beschouwen. Bauer, Plag en Lieber (2013: 458) stellen dat er twee verschillende soorten blends bestaan in het Engels. Beide komen in zoverre overeen dat ze bestaan uit aan elkaar gekoppelde niet-zelfstandige delen van basiswoorden. Het ene type combineert het beginstuk van het eerste, het linker, basiswoord met het staartstuk van het tweede, het rechter, basiswoord, zie voorbeelden in (8). Het andere type voegt het begindeel van beide basiswoorden samen. Voorbeelden worden gegeven in (9). De samenvoegende delen zijn gecursiveerd.
(8)
conculega
$<$ concurrent
krommunicatie $<\mathrm{kr}$ om
flexitariër
$<$ flexibel
+ collega
+ communicatie
+ vegetariër
(9)
Europol
biohistoricus
flexwerk
< Europees
$<$ biograaf
$<$ flexibel
+ politie
+ historicus
+ werk

Als we de basiswoorden steeds in twee delen verdelen, dus het linker basiswoord in A \& B en het rechter basiswoord in $\mathrm{C} \& \mathrm{D}$, dan is het eindproduct van (8) AD en dat van (9) AC of AC(D).
$\begin{array}{lll}\text { (8a) } & \text { A } & \text { B } \\ \text { concu } & \text { rrent }\end{array}$
$+$$$
\text { C }
$$$$
\text { co llega }
$$
A
concu llega
(9a) A
$\begin{array}{ll}\text { A } & \text { B } \\ \text { Euro } & \text { pees }\end{array}$
$+\quad$ C D
pol itie
A $\mathrm{C}$
Euro pol

In het Nederlands zijn AC-combinaties betrekkelijk schaars. In het Engels is het een veel voorkomend patroon. De delen A en C zijn gecursiveerd.

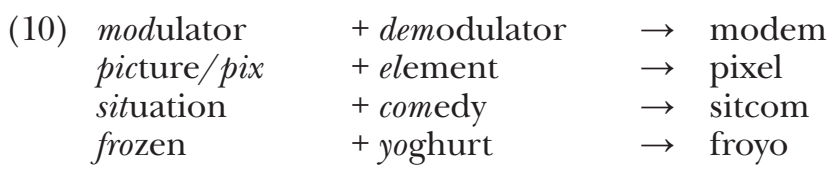


AC combinaties lijken te bestaan uit twee van rechts naar links verkorte vormen, zogenaamde 'back clippings'. Standaardvoorbeelden van back clippings zijn:

(11a) Nederlands

luit
Juf

$<$ luitenant

$<$ juffrouw

$<$ Japanner (11b) Engels

tram < tramway

pram < perambulator

vet $<$ veterinary or veteran

Omdat AC combinaties een samenstelling lijken van twee clipped vormen, worden zij ook 'clipped compounds'of çlipping compounds'genoemd (Bauer, Lieber en Plag 2013: 458). Spencer (1998) en Hamans (2018) gebruiken de term 'stub compounds'. Omdat de afgeknotte stubs 'stompen', anders dan normale clippings zelden of nooit tot vrije vormen leiden ( cf. Hamans 2018b), krijgt de term 'stub compounds' hier de voorkeur.

\section{Kenmerken van stub compounds}

Stub compounds gedragen zich in een aantal opzichten als gewone samenstellingen, bijvoorbeeld waar het gaat om het klemtoonpatroon.

(12) (12a)

$\begin{array}{llll}\text { Eúropol } & \leftrightarrow & \text { eurocráát } & \text { (< Európa }+ \text { bureaucráát }) \\ \text { fléxwerk } & \leftrightarrow & \text { flexitáriër } & (<\text { flexíbel }+ \text { vegetáriër }) \\ \text { bíotech(nologie) } & \leftrightarrow & \text { technobéét } & (<\text { techníek }+ \text { analfabéét })\end{array}$

De vormen in het linker rijtje - (12a), het Europol-rijtje - zijn alle drie AC formaties, stub compounds. De vormen in (12b) AD combinaties. De AC formaties hebben, als waren ze gewone samenstellingen, de klemtoon op het eerste deel. Zij volgen de Compound Stress Rule (Chomsky en Halle 1968: 104), die zowel voor het Engels als het Nederlands geldt (Booij 1995: 115). Deze regel zegt dat bij samenstellingen het eerste lid, het linkerdeel, de klemtoon krijgt. Zie bijvoorbeeld:

\section{(13) húísdeur plákband róódborst}

Maar dit is niet het enige punt waarop stub compounds overeen lijken te komen met samenstellingen. Het rechterdeel is, net als bij gewone samenstellingen, het formele en semantische hoofd. Zij volgen de Righthand Head Rule (Williams 1981) die zowel voor het Engels als het Nederlands geldt. Voor de argumentatie relevante formele kenmerken zijn gecursiveerd:

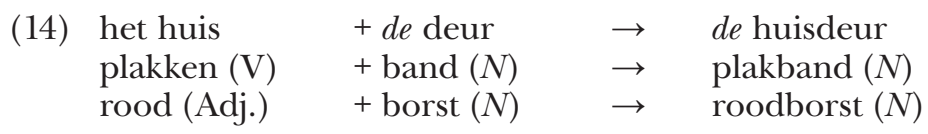


In huisdeur bepaalt het rechterdeel de deur het woordgeslacht. In plakband bepaalt het rechterdeel, het zelfstandig naamwoord band, de woordsoort. In roodborst gebeurt hetzelfde. Het rechterdeel of tweede lid is dus het formele hoofd van deze samenstellingen. Dit rechter deel is bovendien het semantische hoofd: een huisdeur is een deur en geen huis, etcetera, hetgeen aangeeft dat het rechterdeel ook semantisch regeert.

Bij de schaarse Nederlandse AC samenstellingen is het formele hoofd moeilijker aan te geven, hoewel een vorm als flexwerk, een samenstelling van een afgeknot adjectief en het substantief werk, uiteindelijk ook het woordgeslacht en woordsoortkarakter van het rechterdeel, werk, overneemt. Het is namelijk het flexwerk en flexwerk is een substantief. Semantisch ligt de zaak veel eenvoudiger: flexwerk is een vorm van werk en biotech is in eerste instantie een vorm van technologie en niet van biologie. Europol is de naam voor het Europese samenwerkingsverband van politiediensten.

Samengevat: AC formaties volgen de Compound Stress Rule en zijn onderhevig aan de Righthand Head Rule. Dit impliceert dat ze in feite gewone samenstellingen zijn, hoewel samenstellingen van ingekorte woorden, die niet noodzakelijkerwijze zelf al vrij voorkomen en dus nog geen vrije morfemen hoeven te zijn.

\section{AD blends}

Zoals de voorbeelden uit het rechterrijtje van (12) lieten zien, volgen AD formaties de Compound Stress Rule niet. Ze onderscheiden zich in dit opzicht dus van stub compounds. De vraag is of ze dat qua andere kenmerken ook doen. Allereerst wordt onderzocht of AD formaties wellicht ook een formeel en semantisch hoofd hebben. Relevante data zijn gecursiveerd.

(15a) Potel 'hotel' voor Poolse werknemers

de Polen $\quad+$ het hotel $\rightarrow \quad$ het Potel

(15b) preferendum: referendum met meer opties (preferenties) de preferentie + het referendum $\rightarrow$ het preferendum

(15c) scheit: nakomeling van schaap en geit het schaap + de geit $\rightarrow d e$ scheit

He rechterdeel in deze AD formaties is het hoofd want het bepaalt het woordgeslacht. Bovendien is het rechterdeel in (15a) en (15b) ook semantisch het hoofd: Potel is een speciaal hotel en een preferendum is een bepaald type referendum. In (15c) scheit is eerder sprake van een dvanda blend, vergelijkbaar met een dvanda compositum als singer-songwriter of kardinaal-politicus waarbij geen van de samenstellende delen prioriteit heeft over de ander.

Het Duits kent voorbeelden die vergelijkbaar zijn met de Nederlandse in (15a-c). 
(16a) Kurlaub 'vakantie gecombineerd met een kuur in een kuuroord' die Kur $\quad+$ der Urlaub $\rightarrow \quad$ der Kurlaub

(16b) Sportel 'sporthotel' die Sport +das Hotel $\rightarrow \quad$ das Sportel

(16c) Datei 'file' die Daten (pl.) + die Kartei $(s g) \quad \rightarrow \quad$ die Datei $(s g)$

Voorbeelden (16a \&b) komen overeen met de voorbeelden (15a-c). Voorbeeld (16c) is uitzonderlijk, omdat hier een pluralis van een basiswoord gecombineerd wordt met een singularis. De uiteindelijke blend is singularis op grond van het enkelvoudige karakter van het tweede, rechter basiswoord.

Het rechterdeel van een AD- formatie bepaalt niet alleen het woordgeslacht als in (15a-c) en (16a \&b) of het getal zoals in (16c), maar ook tot welke woordsoort de uiteindelijke blend behoort, zoals de voorbeelden in (17) en (18) laten zien. Relevante kenmerken zijn opnieuw gecursiveerd.

$$
\begin{aligned}
& \operatorname{vaag}(\operatorname{Adj}) \quad+\text { vegetariër }(N) \quad \rightarrow \quad \text { vagetariër }(N) \\
& \operatorname{krom}(\operatorname{Adj})+\text { communicatie }(N) \rightarrow \text { krommunicatie }(N) \\
& \text { alernatief }(\operatorname{Adj})+\text { therapeut }(N) \quad \rightarrow \quad \text { alterneut }(N)
\end{aligned}
$$

(18) Duits

(18a) Naktivist 'aktivist die naakt actie voert' nakt $($ Adj) $\quad+$ Aktivist $(N) \quad \rightarrow \quad$ Naktivist $(N)$

(18b) Teuro 'scheldwoord voor dure euro' Teuer $(\operatorname{Adj}) \quad+$ Euro $(N) \quad \rightarrow \quad$ Teuro $(N)$

(18c) herrklären 'mansplain, betuttelende verklaring door een man aan een vrouw' $\operatorname{Herr}(\mathrm{N}) \quad+$ erklären $(V) \quad \rightarrow \quad$ herrklären $(V)$

Samenvattend: het rechterdeel van de AD formaties, in het vervolg blends genoemd, bepaalt het woordgeslacht, het getal en de woordsoort. Bovendien is dit deel vrijwel altijd semantisch leidend. Het rechterdeel is derhalve formeel en semantisch het hoofd. In het woordvormingsproces gedragen blends zich in dit opzicht dus als samenstellingen.

\section{Klemtoon van blends}

Het klemtoonpatroon van blends is echter geenszins dat van samenstellingen, als reeds eerder aangegeven. Blends zijn niet onderhevig aan de Compound Stress Rule, maar volgen of kopiëren het klemtoonpatroon van het tweede, het rechter, basiswoord, dus van het hoofd, zoals onder anderen Beard (1998) en Bat-El en Cohen (2012) hebben vastgesteld voor het Engels. Voor het Nederlands geldt hetzelfde, zoals blijkt uit de data in (19). Het relevante segment is weer gecursiveerd. 
(19)

$\begin{array}{ll}\text { krom } & + \text { communícatie } \\ \text { concurrént } & + \text { colléga } \\ \text { flexíbel } & + \text { vegetáriër } \\ \text { alternatiéf } & + \text { therapéút }\end{array}$

$\rightarrow \quad$ krommunicátie

$\rightarrow \quad$ conculéga

$\rightarrow \quad$ flexitáriër

$\rightarrow \quad$ alternéút

Het kopieergedrag van blends gaat zelfs zo ver dat als het segmentale materiaal van het tweede basiswoord dat klemtoondragend is, gewist wordt, de klemtoon toch geplaatst wordt op de plek waar die in het tweede basiswoord lag. Zie bijvoorbeeld het Engelse woord prestinant, een blend van prestigious en dominant:

(20) prestígious

$$
+ \text { dóminant } \rightarrow \text { préstinant }
$$

In dit voorbeeld ligt de klemtoon op de eerste lettergreep, waar die ook lag in het tweede basiswoord. Het opvallende is evenwel dat de beklemtoonde syllabe van het tweede basiswoord gewist is en niet voorkomt in de uiteindelijke blend. Toch blijft de klemtoon op die eerste lettergreep, terwijl toch de tweede, oorspronkelijk beklemtoonde, lettergreep van het eerste basiswoord deel uitmaakt van de resulterende blend. Deze laatste lettergreep verliest de klemtoon ten faveure van die waarin de klemtoon lag in dóminant.

Voor een goed begrip van het prosodische verschil tussen stub compounds en blends is het zinvol de notie prosodisch woord in te voeren. Het begrip prosodisch woord staat tegenover dat van grammaticaal woord (Booij 1999: 47). Het prosodische woord is het domein van klemtoontoekenning en van fonotactische en segmentale woordniveauregels (Peperkamp 1999: 15). De lengte van een prosodisch woord hoeft niet noodzakelijkerwijze overeen te komen met dat van een morfologisch woord. Neem bijvoorbeeld de samenstelling landengte. De samenstellende delen van dit woord vormen elk een prosodisch woord. De uitspraak is immers / lantentə/ met 'final devoicing' van de slotmedeklinker van land. Ware landengte één prosodisch woord geweest, dan zou de syllabeverdeling als volgt geweest moeten zijn: lan-deng-te. De hiermee corresponderende uitspraak van de /d/ zou stemhebbend hebben moeten zin, hetgeen die niet is. Als we aannemen dat samenstellingen uit twee prosodische woorden bestaan, staat deze / d/ in Auslautpositie en verliest door de regel van 'final devoicing', traditioneel ook wel 'Auslautsverhärtung' genoemd, zijn stemhebbendheid en wordt /t/. Voor het Duitse Abendessen 'avondeten' geldt hetzelfde. Ook hier is de lettergreepverdeling en daarmee samenhangende uitspraak niet aben-dessen, maar verliest de slot -/d/ van het linker woord het kenmerk stemhebbend, omdat Abend een apart prosodisch woord is. Ook het Duits kent immers final devoicing, finale verscherping.

In dit opzicht verschillen blends wezenlijk van samenstellingen, zoals uit het voorgaande duidelijk geworden is. Waar samenstellingen uit twee prosodische woorden bestaan, kopiëren blends de prosodie van het tweede basiswoord. In vrijwel alle gevallen is dat één prosodisch woord en daardoor vormen blends ook slechts één prosodisch woord. 


\section{Syllabische structuur van blends}

In (3) is getoond dat er weinig systematiek te ontdekken valt in wat er geschrapt wordt in de basiswoorden die uitgangspunt vormen voor blends. Als er niet naar het concrete segmentale materiaal gekeken wordt, maar naar syllabeconstituenten blijkt er evenwel wel degelijk een herkenbaar patroon ten grondslag te liggen aan blends (zie ook Arndt-Lappe - Plag 2012). De samenstellende delen van de uiteindelijke blends zijn gecursiveerd.
(21) brusjes
$<b r$ oers
krommunicatie $<k r$ om
$+\mathrm{z}$ usjes
vechtscheiding $<v$ echt
+ communicatie ${ }^{3}$
+ echtscheiding ${ }^{4}$

In brusjes en krommunicatie is de onset van (de eerste syllabe) van het rechterbasiswoord gewist. De daardoor openvallende structurele syllabische plek is ingevuld door de onset van het linkerbasiswoord. Omdat syllabische onsets in het Nederlands uit een, twee en soms zelfs uit drie medeklinkers kunnen bestaan is het geen probleem dat de plek van de medeklinkers /z/ en / k/ door consonantclusters als /br/ en / kr/ gevuld wordt. De syllabische structuur van het tweede basiswoord blijft onaangetast voortbestaan.

In vechtscheiding speelt in wezen niets anders. De eerste lettergreep van echtscheiding heeft een lege onset. Die mag, zonder dat er iets aan de structuur van deze syllabe verandert, gevuld worden. Dat doet de onset, /v/, van vecht. Theoretisch had deze lege onset ook met een consonantcluster gevuld kunnen worden: vlechtscheiding is een uitstekend, mogelijk Nederlands woord.

Lang niet altijd gaat het echter om wissen van een onset, zoals de data in (22) laten zien.
(22) flexitariër
$<$ flexi bel + vege tariër
eurocraat
$<$ Euro pa
+ bureau craat
alterneut
$<$ altern atief + therap eut

De voorbeelden flexitariër en eurocraat zijn helder: het segmentale materiaal van de twee eerste syllaben van het rechter basiswoord wordt gewist. Op de openvallende, maar structureel nog steeds aanwezige plaatsen worden de eerste twee lettergrepen van de linker basiswoorden ingevoegd. In het geval van alterneut gaat het wissen nog een stapje verder. Van het basiswoord therapeut worden niet alleen de eerste twee syllaben gewist, maar ook de onset van de laatste, de derde lettergreep. Het linker basiswoord alternatief kan dus zijn twee beginsyllaben leveren plus de onset van de derde syllabe. Dit is ook precies wat er gebeurd is: al-ter- $n$ heeft de plaats ingenomen van the-ra- $p$.

3 Krom en communicatie kunnen ook op andere wijzen gesegmenteerd worden. Bijvoorbeeld $k r o m+$ comm unicatie. Voor het eindresultaat en voor de hierna volgende argumentatie maakt het geen verschil welke segmentering gekozen wordt. Ook als het overlappende deel van beide basiswoorden in de uiteindelijke segmentering opgenomen worden, dus krom en c ommunicatie, is er geen probleem. Een ook elders in de grammatica optredende haplologieregel voorkomt dat de uiteindelijke blend in kromommunicatie resulteert.

4 Voor dit voorbeeld geldt mutatis mutandis hetzelfde als wat in de vorige voetnoot werd beweerd ten aanzien van krommunicatie. 
Samenvattend kan gesteld worden dat het eerste basiswoord precies zoveel syllabisch beginmateriaal mag leveren aan de blend als dat er gewist is aan het begin van het tweede basiswoord. Niet altijd is er echter een één op éen relatie tussen gewist en ingevoegd materiaal, zoals blijkt uit de volgende data:
(23a) conculega
$<$ concurrent
+ collega
(23b) anacroniem
$<$ anachronisme
+ acroniem
(23c) democratuur
$<$ democratie
+ dictatuur

In (23a) is de eerste lettergreep / ko/ of / ko/ van collega gewist. Daarvoor in de plaats zijn echter twee syllaben ingevoegd / konky/. In (23b) speelt iets vergelijkbaars. Hier is de eerste lettergreep van acroniem, /a/, gewist en vervangen door de eerste twee syllaben van ana-chronisme. Een alternatieve analyse is dat er niets geschrapt is in acroniem en dat op de potentieel vrije plaats van een pre-initiële syllabe de eerste syllabe van an-achronis$m e$ is ingevuld. In (23c) tenslotte zijn van dictatuur de eerste syllabe en de onset van de tweede gewist / dikt/. Invoeging van overeenkomstig segmentaal materiaal van democratie zou een niet-adequate blend dematuur opgeleverd hebben.

Voor een geslaagde blend speelt er namelijk nog iets anders dan alleen de formele gelijkheid tussen gewist en ingevoegd syllabisch materiaal. Een blend is pas geslaagd als de luisteraar/lezer in staat is de combinatie van ingekorte delen van twee basiswoorden te interpreteren. Dit geldt natuurlijk in het bijzonder bij neologistische blends; langer bestaande blends zijn immers gelexicaliseerd en als zodanig in het lexicon en begrippenapparaat van de taalgebruiker opgenomen. Voor een zinnige interpretatie is het nodig dat de samenstellende delen vrij gemakkelijk te herleiden moeten zijn tot hun basiswoorden. Dit zou men het terugvindbaarheidcriterium kunnen noemen. Zijn de samenstellende delen niet eenvoudig herleidbaar tot de oorspronkelijke basiswoorden, dan wordt er tekort gedaan aan de begrijpelijkheid. Dat is het geval met dematuur. Formeel is dematuur een prima blend, interpretatief daarentegen niet. De mogelijke betekenis kan niet achterhaald worden door gebrek aan voldoende overeenkomst met het linker basiswoord. Het segment dem bevat niet voldoende fonologisch materiaal om eenduidig, of in elk geval duidelijk, naar het basiswoord democratie herleid te kunnen worden. Het beginsegment dem kan evengoed afkomstig zijn van woorden als demagoog, dement, demissionair, demon, demonstratie, demoraliseren of demotiveren als van democratie.

In het geval van conculega zou invoeging van slechts een lettergreep geleid hebben tot een vorm identiek aan het rechterbasiswoord collega, ergo tot een vorm die op geen enkele wijze herleidbaar is tot het linker basiswoord concurrent. Vanwege de te geringe herleidbaarheid tot of herkenbaarheid van het linker basiswoord is er op de opengevallen plaats in het rechter basiswoord van de voorbeelden (23 a-c) daarom steeds een extra initiële syllabe toegevoegd, iets wat gedaan kan worden zonder in strijd te komen met de fonotactische en syllabische regels van het prosodisch woordniveau van het tweede basiswoord en dus van de uiteindelijke blend. 


\section{Conclusie}

Blends kopiëren, zoals hier aangetoond is, het klemtoonpatroon en de syllabische structuur van het rechterbasiswoord, dat ook het formele en vaak tevens semantische hoofd levert van de resulterende blend. Qua prosodie en syllabestructuur vormen blends steeds één prosodisch woord. In dit opzicht zijn blends dus ongeleed.

Waar het gaat om woordgeslacht, getal en woordsoort gedragen blends zich echter als samenstellingen en zijn ze derhalve als geleed te beschouwen. Vandaar dat het mogelijk is blends te beschrijven als een tussencategorie tussen gelede en ongelede woorden. Of als een overgangsvorm, als een brug tussen gelede en ongelede woorden.

\section{Bibliografie}

Arndt-Lappe, Sabine - Plag, Igno (2012): Phonological Variability in English Blends, paper presented at the Conference "Data-Rich Approaches to English Morphology: From corpora and experiments to theory and back”. Wellington New Zealand, 4-6 July 2012.

Aronoff, Mark (1976): Word Formation in Generative Grammar. Cambridge mass.: MIT Press.

Bat-El, Outi - Cohen, Evan-Gary (2012): Stress in English blends: A constraint based analysis. In: Renner, Vincent - Maniez, François \& Arnaud, Pierre (eds.), Crossdisciplinary Perspectives on Lexical Blending. Berlin: De Gruyter Mouton: pp. 193-211.

Bauer, Laurie (1983): English word-formation. Cambridge: Cambridge University Press.

Bauer, Laurie (1988): Introducing Linguistic Morphology. Edinburgh: Edinburgh University Press.

Bauer, Laurie - Liber, Rochelle \& Plag, Ingo (2013): English Morphology. Oxford: Oxford University Press.

Beard, Robert (1998): Derivation. In: Spencer, Andrew - Zwicky, Arnold M. (eds.): The Handbook of Morphology. Oxford: Blackwell: pp. 44-65.

Booij, Geert (1995): The Phonology of Dutch. Oxford: Clarendon Press.

Booij, Geert (1999): The role of the prosodic word in phonotactic generalizations. In: Hall, T.Alan - Kleinhenz, Ursula (eds.): Studies on the Phonological Word. Amsterdam: John Benjamins: pp. $47-71$.

Booij, Geert (2019): The Morphology of Dutch. Oxford: Oxford University Press. Second edition. Booij, Geert - Van Santen, Ariane (2018): Morfologie. De woordstructuur van het Nederlands. Amsterdam: Amsterdam University Press. $3^{\mathrm{e}}$ geheel herziene druk.

Chomsky, Noam - Halle, Morris (1968): The Sound Pattern of English. New York: Harper \& Row. Fradin, Bernard (2000): Combining forms, blends and related phenomena. In: Doleschal, Ursula - Thornton, Anna M. (eds.): Extragrammatical and Marginal Morphology. Munich: Lincom: pp. 11-59.

Grésillon, Almuth (1984): La règle et le monster: le mot-valise. Tübingen: Max Niemeyer Verlag. Hamans, Camiel (2018a): Between stub compounds and blends. In: Masiulionyté, Virginija - Volungevičiené, Skaisté (eds.): Fremde und Eigene Sprachen. Linguistische Perspektive, Foreign and Own Languages. Linguistic Perspectives. Akten des 51 Linguistischen Kolloquiums in Vilnius 2016, Selected papers of the $51^{\text {st }}$ Linguistics Colloquium in Vilnius 2016. Berlin: Peter Lang: pp. 353-371. 
Hamans, Camiel (2018b): Between Abi and Propjes: Some remarks about clipping in English, German, Dutch and Swedish. In: Skase, Journal of Theoretical Linguistics [online]. 15, 2, 24-59. Available at: http://www.skase.sk./Volumes/JTL37/pdf_doc/03.pdf (08.08.2019).

Haspelmath, Martin (2002): Understanding Morphology. London: Arnold.

Kastovsky, Dieter (2009): Astronaut, astrology, astrophysics: About Combining Forms, Classical Compounds and Affixoids. In: McConchie, Roderick W. - Honkapohja, Alpo \& Tyrkkö, Jukka (eds.). Selected Proceedings of the 2008 Symposium on New Approaches in English Historical Lexis (HEL-LEX 2).

Peperkamp, Sharon (1999): Prosodic Words. In: Glot International 4,4: pp. 15-16.

Rainer, Franz (1993): Spanische Wortbildungslehre. Tübingen: Niemeyer.

Spencer, Andrew (1991): Morphological Theory: an Introduction to Word Structure in Generative Theory. Cambridge: Cambridge University Press.

Spencer, Andrew (1998): Morphophonological Operations. In: Spencer, Andrew and Zwicky, Arnold M. (eds.), The Handbook of Morphology. Oxford: Blackwell: pp. 123-143.

Uhlenbeck, Eugenius M. (Bob) (1959): Taalwetenschap. Den Haag: H.L. Smits.

Williams, Edwin (1981): On the notions 'lexically related' and 'head of a word'. In: Linguistic Inquiry 12 , pp. $245-274$

Camiel Hamans / c.s.j.m.hamans@uva.nl/hamans@telfort.nl

Center for Language and Communication

Universiteit van Amsterdam, NL 
